\title{
Two cases of malignant peritoneal mesothelioma without asbestos exposure
}

Dwa przypadki złośliwego międzybłoniaka otrzewnej bez ekspozycji

\author{
na działanie azbestu w wywiadzie
}

Department of Obstetrics and Gynecology, Dong-A University, College of Medicine, 26, Daesingongwon-ro, Se0-gu, Busan, 49201, Republic of Korea

Correspondence: Jung-Woo Park, MD, PhD, Department of Obstetrics and Gynecology, Dong-A University, College of Medicine, 26, Daesingongwon-ro, Se0-gu, Busan, 49201, Republic of Korea,

tel.: +8251240 5090, fax: +8252244 9553, e-mail: mdpjw1216@gmail.com

Abstract Malignant peritoneal mesothelioma is a rare disease and usually develops in individuals aged between 50 and 69 years. Exposure to asbestos is reported in $80 \%$ of cases of pleural mesothelioma, but in peritoneal type such an exposure is noted in only $8 \%$ of cases. Prognosis is poor for mesothelioma with a median survival of $<1$ year. Here, we report two cases of malignant peritoneal mesothelioma without history of exposure to asbestos.

Keywords: malignant peritoneal mesothelioma, peritoneal malignancy, surgical treatment

Streszczenie Złośliwy międzybłoniak otrzewnej jest rzadką chorobą i zwykle rozwija się u osób w wieku od 50 do 69 lat. Ekspozycję na azbest odnotowano u $80 \%$ chorych z międzybłoniakiem opłucnej i jedynie u $8 \%$ z międzybłoniakiem otrzewnej. Rokowanie jest złe, a mediana przeżycia wynosi $<1$ rok. W pracy przedstawiamy dwa przypadki złośliwego międzybłoniaka otrzewnej bez narażenia na działanie azbestu w wywiadzie.

Słowa kluczowe: złośliwy międzybłoniak otrzewnej, nowotwór otrzewnej, leczenie chirurgiczne 


\section{INTRODUCTION}

$\mathrm{M}$ alignant peritoneal mesothelioma (MPM) is an extremely rare disease, with approximately 250-500 cases annually in the United States ${ }^{(1)}$. Although the etiology of mesothelioma is not yet fully understood, it has been associated with industrial pollutants and mineral exposures ${ }^{(2,3)}$. The most common carcinogen that leads to the development of pleural mesothelioma is asbestos, with approximately $80 \%$ of cases associated with asbestos exposure ${ }^{(4,5)}$. Although a strong relationship between asbestos exposure and development of pleural mesothelioma has been shown, such a strong relationship has not been found with MPM. The most common initial complaint is abdominal distension, followed by nonspecific abdominal pain. Patients also often complain of nausea, weight loss, satiety, and fever of unknown origin. Due to the vague and nonspecific nature of its symptoms, serum marker levels, and radiologic imaging findings, MPM is difficult to diagnose ${ }^{(6)}$. As a result of the delay in the onset of patient's symptoms and diagnosis, most MPMs spread throughout the abdominal cavity.

Here, we report two cases of MPM without exposure to asbestos.

\section{CASE PRESENTATION}

\section{Case 1}

A 27-year-old woman (gravida 0, para 0 ) presented to our hospital with abdominal distension and weight loss of $10 \mathrm{~kg}$ in 2 months. The patient had no underlying diseases and no history of asbestos exposure. Blood test results showed slightly increased CA-125 levels to $77 \mathrm{U} / \mathrm{mL}$ (normal range, 0-35) and normal other tumor marker levels. In the initial abdominal computed tomography (CT), a large amount of ascites was noted in the pelvic cavity, and multiple growing papillary lesions with solid portion around both adnexa and enhanced nodules

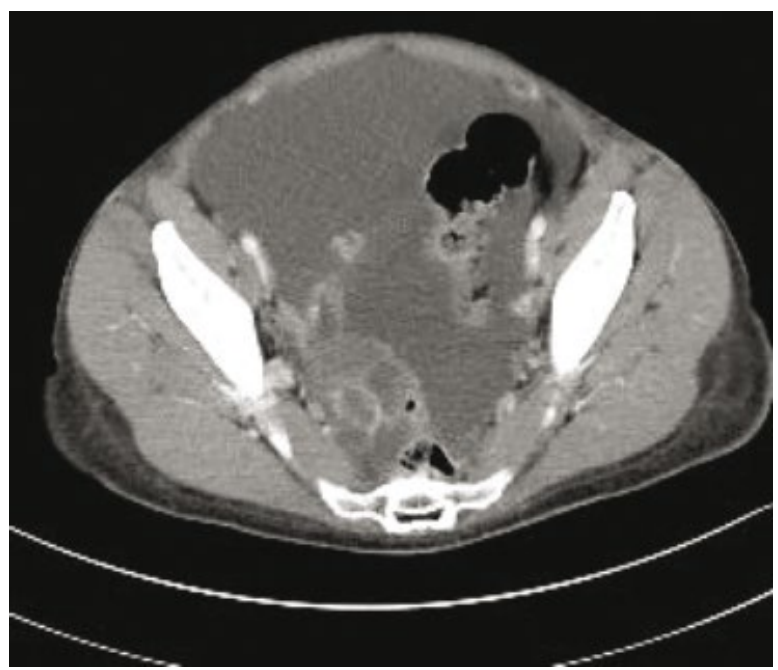

Fig. 1. APCT shows a large amount of ascites, multiple growing papillary lesions with solid portion around both adnexa

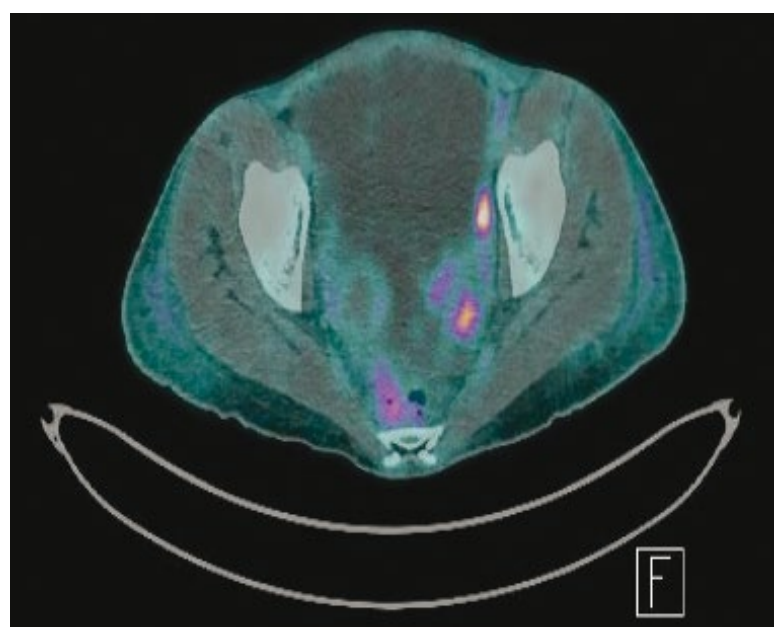

Fig. 2. PET-CT shows cystic masses with hypermetabolic solid portion in the pelvic cavity

along the peritoneum were observed (Fig. 1). Chest CT showed pleural effusion in both lungs and no other specific findings. Positron emission tomography-computed tomography (PET-CT) showed cystic masses with hypermetabolic solid portion in the pelvic cavity (Fig. 2). The cytologic findings of ascites and pleural fluid were consistent with malignant mesothelioma. The patient underwent optimal cytoreductive surgery; total hysterectomy, bilateral salpingo-oophorectomy and bilateral pelvic lymph node dissection, para-aortic lymph node dissection, and peritonectomy. Pathological examination showed MPM in the peritoneum and metastatic lesions in other tissues. Immunohistochemical staining was positive for anti-mesothelial antibody (Fig. 3).

Three weeks postoperatively, she started pemetrexed-cisplatin chemotherapy. On completion of the five cycles of chemotherapy, the patient complained of severe abdominal pain. Followup chest CT showed newly developed multiple lymph nodes in the left supraclavicular, mediastinal, and axillary areas, and PET-CT confirmed these findings. The chemotherapy regimen was changed to mitomycin/vinblastine/cisplatin, and up to six cycles were completed. However, lymph node, lung, and liver

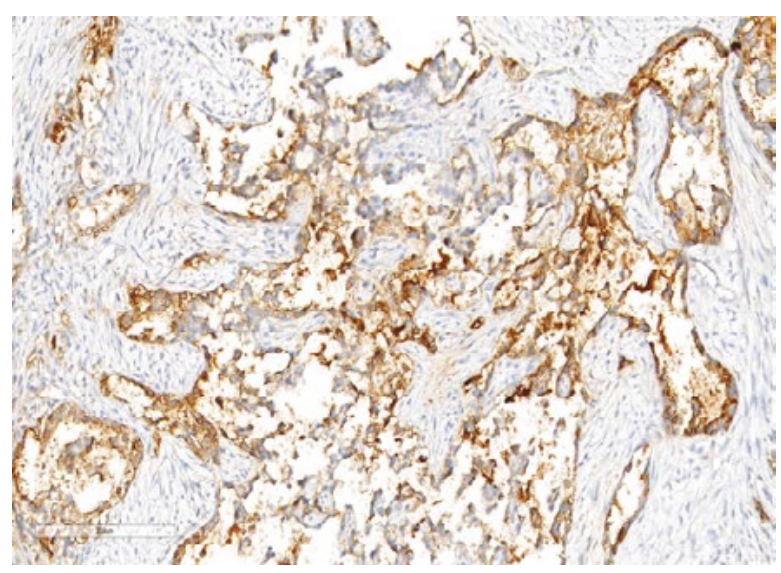

Fig. 3. Immunohistochemical staining positive for anti-mesothelial antibody 


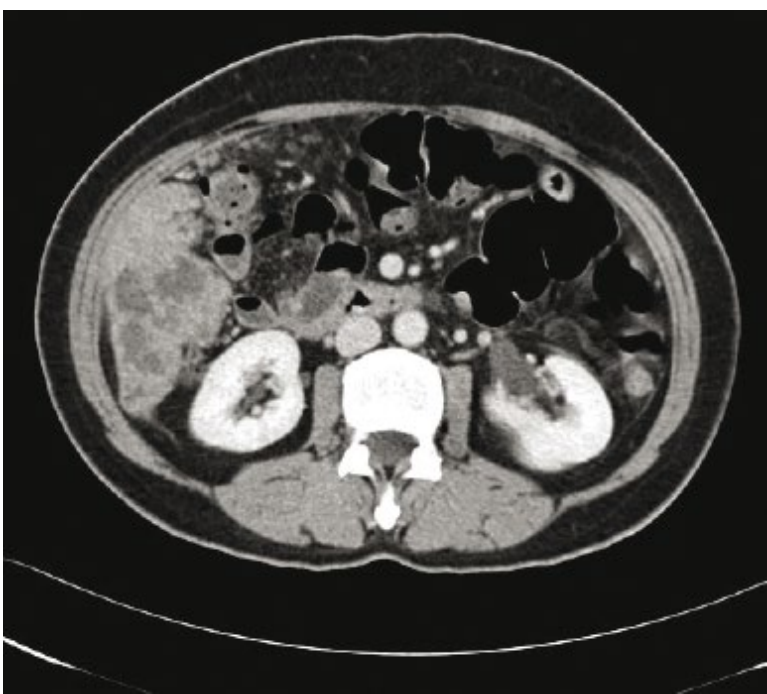

Fig. 4. Abdominal CT showing $9 \times 5 \mathrm{~cm}$ heterogeneously enhancing mass in the mesentery and omentum

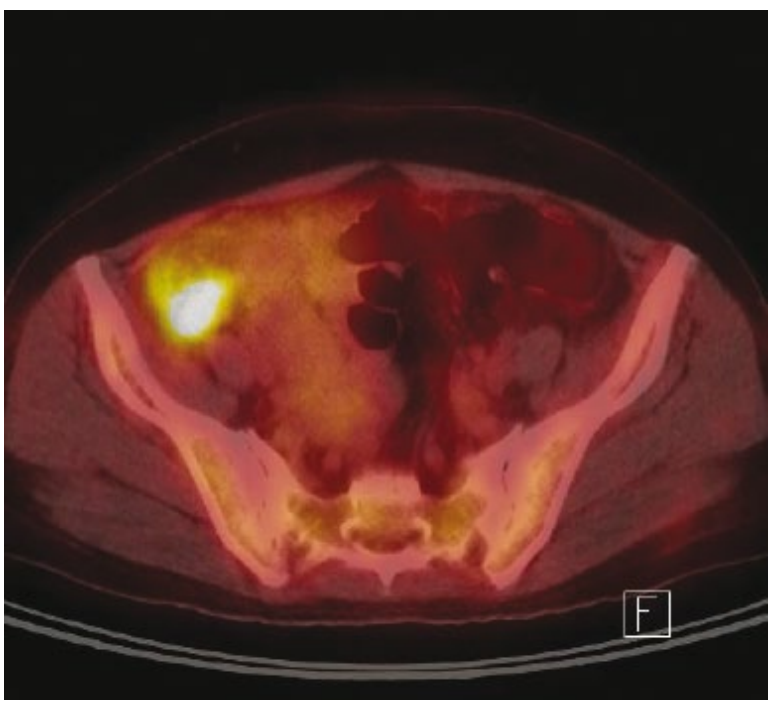

Fig. 5. PET-CT showed malignancy in the paracolic gutter

metastases persisted. Moreover, the patient was no longer able to undergo chemotherapy due to pancytopenia. Eventually the patient died 18 months after cancer diagnosis.

\section{Case 2}

A 53-year-old Asian woman (gravida 3, para 3) was admitted due to flank pain and fever for 4 days. The patient had menopause 3 years earlier and had not received any hormonal therapy. There was no history of underlying disease and no occupational history of asbestos exposure. Blood test results showed increased CA-125 level to $867 \mathrm{U} / \mathrm{mL}$. Other tumor maker levels were normal. Abdominal CT showed a $9 \times 5 \mathrm{~cm}$ heterogeneously enhancing mass in the mesentery and omentum (Fig. 4). Ultrasonography revealed normal uterus and both adnexa. No ascites was observed. PET-CT showed malignancy in the paracolic gutter (Fig. 5).
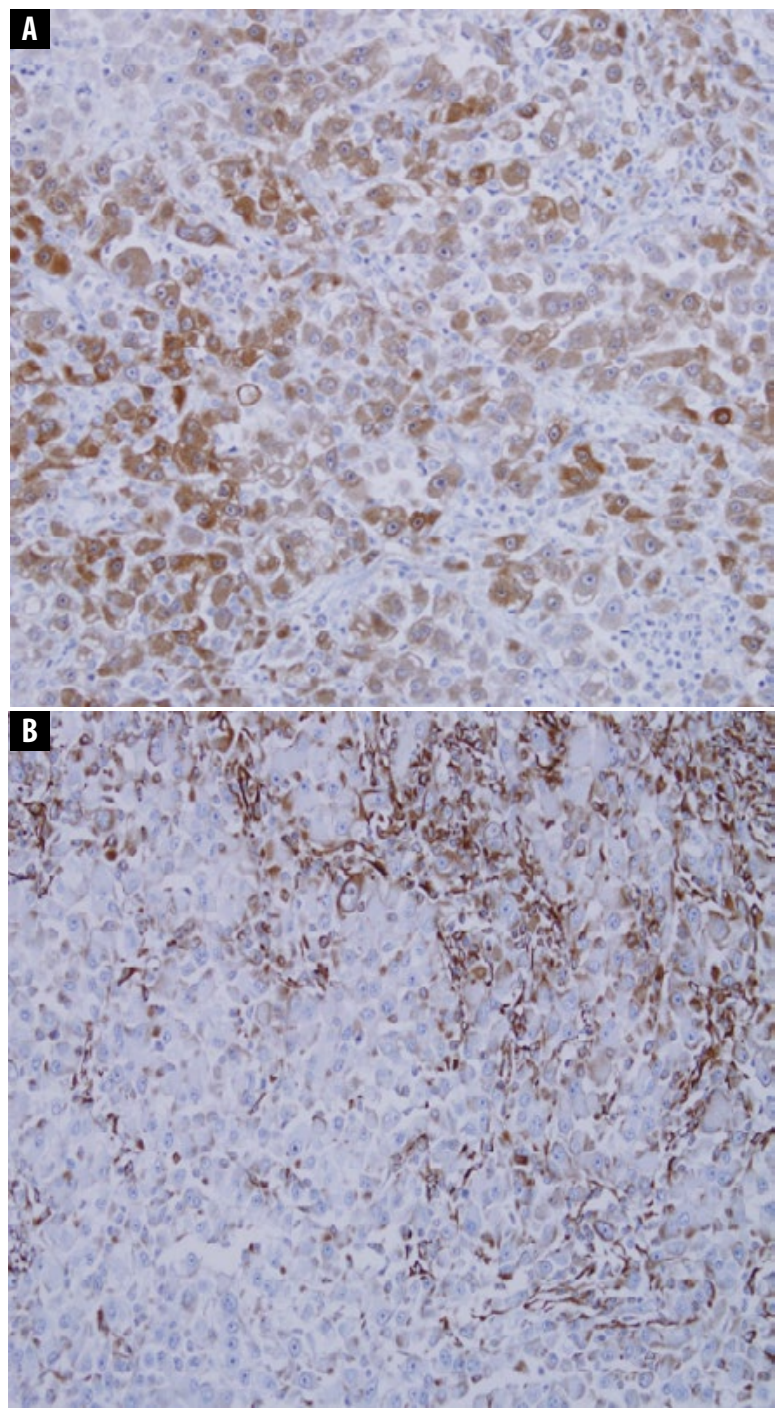

Fig. 6. Immunohistochemical staining positive for anti-mesothelial antibody and calretinin

The patient underwent cytoreductive surgery, i.e. hysterectomy, bilateral salpingo-oophorectomy and pelvic lymph node dissection, para-aortic lymph node dissection, inferior colic omentectomy, and peritonectomy. Pathological examination showed MPM in the peritoneum and metastatic lesions in other tissues. Tumor cells were positive for anti-mesothelial antibody, vimentin, cytokeratin, and calretinin but negative for WT-1, CEA, and CD15 on immunohistochemical staining (Fig. 6).

Three weeks postoperatively, pemetrexed/cisplatin chemotherapy was started. After completion of six cycles of chemotherapy, abdominal and chest CT showed persistent lung and liver metastases. Subsequently, the patient refused further chemotherapy and eventually died 12 months postoperatively.

\section{DISCUSSION}

Mesothelioma is an extremely rare malignant tumor of the serosal membranes, including the pleura, pericardium, peritoneum, and tunica vaginalis of the testis ${ }^{(7)}$. The most common site is the 
visceral pleura, followed by the peritoneum. Pleural mesothelioma is more common than malignant peritoneal mesothelioma, so most studies focused on pleural mesothelioma.

To date, it has been found that there are many causes of mesothelioma, such as asbestos exposure, radiation, infection with simian virus 40 , chronic inflammation, and hereditary disposition ${ }^{(8,9)}$. Exposure to asbestos is reported in $80 \%$ of pleural mesothelioma cases, but in peritoneal type such an exposure is noted only in $8 \%$ of cases $^{(10,11)}$.

MPM is difficult to diagnose due to ambiguous nonspecific symptoms ${ }^{(4,5)}$. The main symptoms are variable due to the spread of the tumor in the abdominal cavity. The most common initial symptom is abdominal distension, which is present in $30-80 \%$ of patients. The second most common symptom is abdominal pain, which is present in $27-58 \%$ of patients. Patients also often complain of nausea, weight loss, and satiety. Blood tests and tumor marker examinations have limited utility in the diagnosis of $\mathrm{MPM}^{(12)}$. Unfortunately, some patients have shown increased CA-125, AFP, CEA, and mesothelin levels, but the sensitivity is too low for diagnostic purposes. There is no specific diagnostic imaging technique, but CT is a widely accepted first-line technique ${ }^{(13)}$. MPM appears as a heterogeneous, solid, soft tissue mass with irregular margins, which is enhanced using contrast agents. Since the symptoms, imaging findings, and serum marker levels are nonspecific, the final diagnosis of MPM is made by pathological evaluation. There is no single immunohistochemical marker specific for $\mathrm{MPM}^{(14,15)}$. Instead, a marker panel is used to distinguish MPM from other tumors that may have similar histologic features. MPM is positive for EMA, CK 5/6, WT-1, calretinin, mesothelin, and anti-mesothelial cell antibody-1, and negative for carcinoma markers such as CEA, Ber-EP4, LeuM1, B72.3, and Bg8 thyroid transcription factor-1.

According to the World Health Organization, MPMs are divided into three histological subtypes (epithelioid, sarcomatoid, and biphasic/mixed). The epithelioid subtype is the most common, accounting for $75 \%$ of MPMs, and has the best prognosis with median survival of 55 months ${ }^{(16,17)}$. Approximately $25 \%$ of MPMs are biphasic, but the sarcomatoid subtype is extremely rare. Both of these subtypes have poor prognosis - in particular the median survival in the biphasic type is 13 months.

Until now, complete cytoreductive surgery and intraperitoneal chemotherapy has become the first-line therapy for MPM. Peritoneal chemotherapy can be delivered in the form of heated intraperitoneal chemotherapy (HIPEC) or early postoperative chemotherapy ${ }^{(18,19)}$. Although systemic chemotherapy has been shown to be effective, it is likely to focus more on targeted molecular pathways in the future. Although not yet fully understood, an ongoing investigation on this treatment method is expected to provide better survival for this currently fatal disease due to aggressive broadspectrum peritonitis.

Therefore, these cases showed that diffuse MPM could develop in individuals younger than 30 and 53 years without history of asbestos exposure. To date, the clinical characteristics, biologic and prognostic factors, and treatment are unclear. Further research is needed to determine the risk factors for diffused MPM, the biphasic type in particular. Since the disease has rapid progression and the prognosis is extremely poor, early diagnosis is important.

\section{Conflict of interest}

No potential conflict of interest relevant to this article was reported.

\section{References}

1. Magge D, Zenati MS, Austin F et al.: Malignant peritoneal mesothelioma: prognostic factors and oncologic outcome analysis. Ann Surg Oncol 2014; 21: 1159-1165.

2. Bridda A, Padoan I, Mencarelli R et al.: Peritoneal mesothelioma: a review. MedGenMed 2007; 9: 32.

3. Teta MJ, Mink PJ, Lau E et al.: US mesothelioma patterns 1973-2002: indicators of change and insights into background rates. Eur J Cancer Prev 2008; 17: 525-534.

4. de Pangher Manzini V: Malignant peritoneal mesothelioma. Tumori 2005; 91: 1-5.

5. Kaya H, Sezgl C, Tanrikulu AC et al.: Prognostic factors influencing survival in 35 patients with malignant peritoneal mesothelioma. Neoplasma 2014; 61: 433-438.

6. Kim J, Bhagwandin S, Labow DM: Malignant peritoneal mesothelioma: a review. Ann Transl Med 2017; 5: 236.

7. Henley SJ, Larson TC, Wu M et al.: Mesothelioma incidence in 50 states and the District of Columbia, United States, 2003-2008. Int J Occup Environ Health 2013; 19: 1-10.

8. Yang H, Testa JR, Carbone M: Mesothelioma epidemiology, carcinogenesis, and pathogenesis. Curr Treat Options Oncol 2008; 9: 147-157.

9. Zervos MD, Bizekis C, Pass HI: Malignant mesothelioma 2008. Curr Opin Pulm Med 2008; 14: 303-309.

10. Broeckx G, Pauwels P: Malignant peritoneal mesothelioma: a review. Transl Lung Cancer Res 2018; 7: 537-542.

11. Boussios S, Moschetta M, Karathanasi A et al.: Malignant peritoneal mesothelioma: clinical aspects, and therapeutic perspectives. Ann Gastroenterol 2018; 31: 659-669.

12. Baratti D, Kusamura S, Martinetti A et al.: Circulating CA125 in patients with peritoneal mesothelioma treated with cytoreductive surgery and intraperitoneal hyperthermic perfusion. Ann Surg Oncol 2007; 14: 500-508.

13. Busch JM, Kruskal JB, Wu B; Armed Forces Institute of Pathology: Best cases from the AFIP. Malignant peritoneal mesothelioma. Radiographics 2002; 22: 1511-1515.

14. Husain AN, Colby TV, Ordóñez NG et al.: Guidelines for pathologic diagnosis of malignant mesothelioma 2017 update of the consensus statement from the International Mesothelioma Interest Group. Arch Pathol Lab Med 2018; 142: 89-108.

15. Robinson BW, Lake RA: Advances in malignant mesothelioma. N Engl J Med 2005; 353: 1591-1603.

16. Liu S, Staats P, Lee M et al.: Diffuse mesothelioma of the peritoneum: correlation between histological and clinical parameters and survival in 73 patients. Pathology 2014; 46: 604-609.

17. Ordóñez NG: The diagnostic utility of immunohistochemistry and electron microscopy in distinguishing between peritoneal mesotheliomas and serous carcinomas: a comparative study. Mod Pathol 2006; 19: 34-48.

18. Feldman AL, Libutti SK, Pingpank JF et al.: Analysis of factors associated with outcome in patients with malignant peritoneal mesothelioma undergoing surgical debulking and intraperitoneal chemotherapy. J Clin Oncol 2003; 21: 4560-4567.

19. Helm JH, Miura JT, Glenn JA et al.: Cytoreductive surgery and hyperthermic intraperitoneal chemotherapy for malignant peritoneal mesothelioma: a systematic review and meta-analysis. Ann Surg Oncol 2015; 22: 1686-1693. 